\title{
Identification and Glass Biodeterioration of Chaetomium globosum TTHF1-3 Isolated from Optical Instrument at Thai Hoa, Nghe An Province
}

\author{
Cao Cuong Ngo ${ }^{1,2}$, Thi Thanh Loi Nguyen ${ }^{2}$, Thi Thu Hong Do ${ }^{1}$, \\ The Anh Luu ${ }^{3}$, Ngoc Tung Quach², Quyet Tien Phi',* \\ ${ }^{I}$ Vietnam-Russia Tropical Centre, Ministry of Defence, 63 Nguyen Van Huyen, Cau Giay, Hanoi, Vietnam \\ ${ }^{2}$ Vietnam Academy of Science and Technology, 18 Hoang Quoc Viet, Cau Giay, Hanoi, Vietnam \\ ${ }^{3} V N U$ Central Institute for Natural Resources and Environmental Studies, \\ 19 Le Thanh Tong, Hoan Kiem, Hanoi, Vietnam
}

Received 27 August 2021

Revised 02 Setptember 2021; Accepted 27 October 2021

\begin{abstract}
The colonization and growth of harmful fungi on the glass surface have caused irreversible damage to optical quality. The present study focused on isolation, identification, and evaluation of glass biodeterioration properties such as organic acid and exopolysaccharide production of fungal strain Chaetomium globosum TTHF1-3 isolated from lens of optical instrument collected at Thai Hoa, Nghe An province. Among 11 fungal isolates exhibiting the glass biodeterioration, the strain TTHF1-3 caused the most glass damage with the hyphal surface coverage reaching $29.77 \pm 1.15 \%$, reduction of light transmission through fungus-inoculated glass of 40-48\%, which corresponded to harmful grade 2 based on the ISO 9022-11:2015 criteria. Under microscopic observation, the fungal strain TTHF1-3 cells showed brown or dark brown color perithecia and ascospores. Based on ITS sequence analyses, the strain TTHF1-3 was found to share $100 \%$ sequence identity with that of C. globosum species available onto GenBank (NCBI). Combining to morphological characteristics, the fungal strain TTHF1-3 was identified as Chaetomium globosum. When incubated on MT1 medium, the $\mathrm{pH}$ values of $C$. globosum TTHF1-3 culture were significantly decreased from 6.5 to $3.12 \pm 0.12$. In addition, fungal strain TTHF1-3 was able to produce $8.2 \pm 0.3 \mathrm{~g} / \mathrm{L}$ exopolysaccharides. The findings in the present study confirmed that C. globosum TTHF1-3 was harmful fungus responsible for glass biodeterioration.
\end{abstract}

Keywords: Aspergillus, biodeterioration, Chaetomium globosum, fungi, ITS sequence, optical glass.

\footnotetext{
* Corresponding author.

E-mail address: tienpq@ibt.ac.vn

https://doi.org/10.25073/2588-1140/vnunst.5315
} 


\title{
Đặc điểm phân loại và đặc tính gây hại kính của chủng nấm Chaetomium globosum TTHF1-3 phân lập từ thiết bị quang học tại Thái Hoà, Nghệ An
}

\author{
Ngô Cao Cường ${ }^{1,2}$, Nguyễn Thị Thanh Lợi ${ }^{2}$, Đỗ Thị Thu Hồng ${ }^{1}$, \\ Lưu Thế Anh ${ }^{3}$, Quách Ngọc Tùng ${ }^{2,3}$, Phí Quyết Tiến ${ }^{2, *}$ \\ ${ }^{1}$ Trung tâm Nhiệt đới Việt Nga, Bộ Quốc phòng, 63 Nguyễn Văn Huyên, Cầu Giấy, Hà Nội, Việt Nam \\ ${ }^{2}$ Viện Hàn lâm Khoa học và Công nghệ Việt Nam, 18 Hoàng Quốc Việt, Cầu Giấy, Hà Nội, Việt Nam \\ ${ }^{3}$ Viện Tài nguyên và Môi truờng, Đại học Quốc gia Hà Nội, \\ 19 Lê Thánh Tông, Hoàn Kiếm, Hà Nội, Việt Nam
}

Nhận ngày 27 tháng 8 năm 2021

Chỉnh sửa ngày 02 tháng 9 năm 2021; Chấp nhận đăng ngày 27 tháng 10 năm 2021

\begin{abstract}
Tóm tắt: Sự xâm nhiễm và sinh trưởng của nấm sợi trên bề mặt thấu kính của thiết bị quang học gây hư hại và ảnh hưởng đến chất lượng quan sát. Nghiên cứu này trình bày kết quả phân lập, phân loại của chủng nấm Chaetomium globosum TTHF1-3 phân lập từ mẫu kính quang học tại Thái Hoà, Nghệ An và đánh giá đặc tính gây hại thông qua khả năng sinh axit hữu cơ và polysaccharide ngoại bào (Exopolysaccharide-EPS). Chủng nấm TTHF1-3 có quả thể màu nâu tối và bào tử màu nâu sẫm. Trong số 11 chủng nấm được xác định gây hai trên kính, chủng TTHF1-3 thể hiện gây hại mạnh nhất với diện tích xâm lấn của sợi nấm trên kính là $29,77 \pm 1,15 \%$, độ truyền ánh sáng qua kính nhiễm nấm giảm 40-48\%, tương ứng mức gây hại 2 theo tiêu chuẩn ISO 9022-11:2015. Kết quả phân loại dựa trên trình tự ITS cho thấy chủng nấm thể hiện sự tương đồng đến $100 \%$ với các chủng thuộc loài Chaetomium globosum trên cơ sở dữ liệu GenBank (NCBI). Kết hợp với đặc điểm hình thái, chủng nấm TTHF1-3 được định danh là $C$. globosum. Chủng $C$. globosum TTHF1-3 sinh axit cao nhất trên môi trường $\mathrm{MT} 1$ với giá trị $\mathrm{pH}$ giảm từ 6,5 xuống còn $3,12 \pm 0,12$. Đồng thời, chủng TTHF1-3 có khả năng sinh 8,2 $\pm 0,3 \mathrm{~g} / \mathrm{L}$ EPS. Kết quả nghiên cứu chứng tỏ, chủng nấm C. globosum TTHF1-3 có các đặc tính gây hại đến vật liệu kính.
\end{abstract}

Tù khóa: Aspergillus, Chaetomium globosum, kính quang học, Nấm, phá huỷ sinh học, trình tự ITS.

\section{1. Đặt vấn đề}

Ăn mòn hay phá huỷ sinh học (biodeterioration) trên chi tiết kính được gây ra bởi các nhóm vi sinh vật khác nhau, trong đó chủ yếu do nấm sợi gây nên. Các nghiên cứu cho thấy nấm sợi có khả năng sinh trưởng và phát triển trên bề mặt thấu kính, làm biến đổi cấu trúc dẫn đến hư hại dưới dạng các vết nứt, rỗ, ăn mòn, đổi màu,... [1]. Đối với thấu kính của thiết bị quang học, nấm phát triển hình thành dạng màng sinh học (biofilm) hay vết lan

\footnotetext{
* Tác giả liên hệ.

Địa chỉ email: tienpq@ibt.ac.vn

https://doi.org/10.25073/2588-1140/vnunst.5315
}

của sợi nấm làm ảnh hưởng đến chất lượng quan sát của thiết bị [2].

Vật liệu kính có thành phần chính là các oxit vô cơ $\left(\mathrm{SiO}_{2}, \mathrm{~B}_{2} \mathrm{O}_{3}, \mathrm{CaO}, \mathrm{MgO}, \mathrm{BaO}, \mathrm{ZnO}\right.$, $\mathrm{PbO}$ và $\mathrm{Al}_{2} \mathrm{O}_{3} \cdot \mathrm{SiO}_{2}$ ). Những thành phần này không thuận lợi cho sự phát triển của vi sinh vật nói chung và nấm sợi nói riêng. Tuy nhiên, sự phát tán của bào tử nấm kết hợp với điều kiện khí hậu (độ ẩm, nhiệt độ, gió), bụi trong không khí là những yếu tố quan trọng dẫn tới sự phát triển của vi nấm trên bề mặt vật liệu thủy tinh $[1,3]$. Với khả năng chuyển hoá các nguồn oxit vô cơ, nấm sinh trưởng trên bề mặt vật liệu kính bằng cách tạo các kênh đi sâu vào bề mặt kính, hoà tan các muối vô cơ, kim loại và hấp thụ các chất dinh dưỡng khác [4]. 
Nhiều công bố chứng minh các sản phẩm trao đổi chất của vi nấm như axit hữu cơ (tạo pH thấp phá hỏng bề mặt kính), polysaccharide ngoại bào (EPS) (giúp nấm sợi bám dính, tạo biofilm, gây mờ kính,...) là tác nhân gây hại đến bề mặt chi tiết kính $[5,7]$. Một số chủng vi nấm gây hại kính cửa sổ có khả năng sinh tổng hợp nhiều loại axit hữu cơ khác nhau như axit oxalic, axit citric $[5,8,9]$ và chelate hoá mạnh các kim loại nặng như $\mathrm{Ca}$, $\mathrm{Cd}, \mathrm{Co}, \mathrm{Cu}, \mathrm{Mg}, \mathrm{Mn}, \mathrm{Sr}, \mathrm{Zn}, \mathrm{Ni}$ và $\mathrm{Pb}$ trong vật liệu kính $[5,10]$. Hơn nữa, khả năng sinh EPS là đặc tính quan trọng của nấm sợi gây hại chi tiết kính, giúp cho các nhóm nấm sợi cơ hội phát triển, lan rộng trên bề mặt, tăng khả năng phá huỷ vật liệu kính $[11,12]$.

Các nghiên cứu trên kính nhà thờ, nhà ở dân dụng, di sản văn hóa đã công bố 24 chi nấm phổ biến gồm Alternaria, Aspergillus, Aureobasidium, Capnobotryella, Chaetomium, Cladosporium, Coniosporum, Didymella, Engyodontium, Fusarium, Geomyces, Hortaea, Kirschsteiniothelia, Leptosphaeria, Myrothecium, Penicillium, Penidiella, Phoma, Rhodotorula, Sistotrema, Stanjemonium, Trichoderma, Ustilago và Verticillium [4, 13, 14]. Trong đó, các chi nấm Aspergillus, Cladosporium và Penicillium được phát hiện với tần suất cao và khá đa dạng trên các mẫu chi tiết kính $[15,16]$.

Hiện nay, trên thế giới chưa có nhiều nghiên cứu về đặc tính gây hại của nấm sợi trên bề mặt thấu kính của thiết bị quan sát như ống nhòm, kính hiển vi, kính thiên văn, kính trên ô tô, máy bay,... Tại Việt Nam, các nghiên cứu về nấm sợi trên vật liệu kính chưa được thực hiện nhiều. Giai đoạn 1963 - 1975, Đ. V. H. Miên và cộng sự đã phân lập được 168 chủng nấm sợi từ 1200 thiết bị quan sát, trong đó phân loại 13 chủng thuộc chi Aspergillus, 21 chủng thuộc chi Penicillium [17]; V. M. Thành và cộng sự đã phân lập 4 chủng nấm gồm Cladosporium tenuissium, Ramichloridium sp., Scopulariopsis brumptii và một chủng chưa định danh từ thiết bị quan sát sử dụng trong môi trường biển đảo [18]. Các nghiên cứu nhìn chung chưa đánh giá đặc tính gây hại của nấm và chỉ dừng lại ở phân lập và phân loại nấm qua đặc điểm hình thái. Vì vậy, trong nghiên cứu này, các mẫu thấu kính ống nhóm nhiễm nấm tại Thái Hòa, Nghệ An được thu thập để phân lập và bước đầu nghiên cứu đặc tính gây hại của chủng nấm gây hại mạnh Chaetomium globosum TTHF1-3 để tạo cơ sở cho nghiên cứu và phòng trừ nấm sợi trên vật liệu kính.

\section{2. Đối tượng và phương pháp nghiên cứu}

2.1. Thu thập mẫu kinh nhiễm nấm và phân lập nấm sợi

Tổng số 05 ống nhòm $\mathrm{ON} 8 \times 30$ (sản xuất tại xí nghiệp Quang điện 23, Việt Nam) (Hình 1A) có thấu kính bị nhiễm nấm (Hình $1 \mathrm{~B}$ ) được thu thập tại Thái Hoà, Nghệ An (tọa độ: $19^{\circ} 12^{\prime} 0^{\prime \prime} \mathrm{N} 105^{\circ} 30^{\prime} 0^{\prime \prime} \mathrm{E}$ ) vào tháng $9 / 2017$. Nấm sợi được phân lập theo phương pháp của Hayes (1965) và GOST 9053-75 (1975) kèm một số hiệu chỉnh: dùng tăm bông vô trùng quết lên bề mặt vật kính bị nhiễm nấm; cho tăm bông vào ông nghiệm chứa nước cất vô trùng chứa $0,005 \%$ Tween 80 , lắc 200 vòng/phút trong 30 phút. Hút $0,1 \mathrm{ml}$ dịch pha loãng và chang trên đĩa Petri chứa môi trường thạch Czapek-Dox, nuôi ở $28{ }^{\circ} \mathrm{C}$ trong 48-72 giờ $[19,20]$. Các khuẩn lạc riêng rẽ được tách và làm sạch trên môi trường Czapek-Dox. Mật độ nấm được tính bằng tổng số khuẩn lạc nấm trên $1 \mathrm{~cm}^{2}$ diện tích thấu kính nhiễm nấm.

\subsection{Nghiên cúu đặc điểm hình thái của các chủng} nấm sợi

Các chủng nấm được nuôi ở $28^{\circ} \mathrm{C}$ trên môi trường thạch Czapek-Dox có gắn kính lamen đặt nghiêng. Sau 72 giờ, hình thái cuống sinh bào tử (độ phóng đại $\mathrm{x} 400$ lần) và bào tử (x1000 lần) được quan sát dưới kính hiển vi [21].

2.3. Đánh giá mức độ gây hại của nấm sợi trên kinh trong điều kiện in situ

Mức độ gây hại của nấm trên kính được đánh giá theo tiêu chuẩn ISO 9022-11:2015 https://www.iso.org/standard/67535.html) như sau: 
các chủng nấm được nuôi cấy trên đĩa môi trường $\mathrm{PDA}$ ở $30^{\circ} \mathrm{C}$ trong 2 tuần để thu nhận bào tử. Hòa tan bào tử trong dung dịch khoáng $(\mathrm{g} / \mathrm{L}): 0,7$ g $\mathrm{KH}_{2} \mathrm{PO}_{4} ; 0,7$ g K $\mathrm{K}_{2} \mathrm{HPO}_{4} ; 1,0 \mathrm{~g}$ $\mathrm{NH}_{4} \mathrm{NO}_{3} ; 0,7 \mathrm{~g} \mathrm{MgSO}_{4} .7 \mathrm{H}_{2} \mathrm{O} ; 0,005 \mathrm{~g} \mathrm{NaCl}$; 0,002 g FeSO $4.7 \mathrm{H}_{2} \mathrm{O} ; 0,002$ g $\mathrm{ZnSO}_{4} .7 \mathrm{H}_{2} \mathrm{O}$ $0,001 \mathrm{~g} \mathrm{MnSO}_{4} .7 \mathrm{H}_{2} \mathrm{O} ; \mathrm{pH} 7,0$ và $0,05 \%$ Tween 80. Phun $0,5 \mathrm{ml}$ dung dịch có $10^{6}$ bào tử $/ \mathrm{mL}$ lên bề mặt tấm kính vô trùng $(10 \mathrm{~cm} \times 20 \mathrm{~cm})$ và ủ ở $30^{\circ} \mathrm{C}$, độ ẩm $90 \pm 2 \% \mathrm{RH}$ để kích thích bào tủ nảy mầm. Mẫu kính đối chứng được chuẩn bị tương tự như trên và sử dụng dung dịch khoáng không có bào tử nấm. Sau thời 28 ngày, đánh giá sự sinh trưởng của nấm trên bề mặt kính bằng theo tỷ lệ diện tích kính bị nấm xâm nhập (theo tiêu chuẩn ISO 9022-11:2015) và ghi lại hình ảnh bởi phần mềm ImageJ (ver.1.51, Bethesda, Mỹ) [11, 12].

\subsection{Xác định độ truyền qua ánh sáng của kính}

Các mẫu kính nhiễm nấm sau 28 ngày thử nghiệm được làm sạch bằng cồn $70 \%$ và giữ ổn định ở $23 \pm 5{ }^{\circ} \mathrm{C}$, độ ẩm $60 \% \mathrm{RH}$ trong 2 giờ. Chiếu chùm tia ánh sáng trong dải bước sóng 400 đến $800 \mathrm{~nm}$ qua mẫu kính trong buồng đo máy quang phổ UV-VIS 2550 (Labomed, Mỹ). Ghi nhận kết quả tương quan về bước sóng, hệ số hấp thụ và mức độ truyền qua của ánh sáng đối với mỗi phép đo [22].

\subsection{Phân loại chủng nấm TTHF1-3 bằng phân} tích trình tư vùng gen ITS

DNA tổng số của nấm được tách chiết bằng KIT Fungi/Yeast DNA Extraction (Norgen, Canada). Trình tự ITS được nhân lên từ DNA tổng số với cặp mồi ITS1F (5'- CTT GGT CAT TTA GAG GAA GTA A - 3'); ITS4 (5' - TCC TCC GCT TAT TGA TAT GC - 3') [23]. Sản phẩm PCR được tinh sạch, giải trình tự trên máy đọc trình tự động $\mathrm{ABI}$ PRISM $® 3100$-Avant Genetic Analyzer (Applied Biosystems, Foster City, CA, USA). Trình tự nucleotide được xử lý bằng phần mềm BioEdit (ver. 6.0.7, Mỹ) và so sánh với các trình tự tương ứng được đăng ký trên GenBank (www.ncbi.nlm.nih.gov) bằng công cụ BLAST. Cây phả hệ được xây dựng bằng phần mềm Mega (ver.7) bằng phương pháp
Maximum-likelihood dựa trên thuật toán Gamma và Kimura 2 với giá trị bootstrap 1000 [24, 25].

2.6. Đánh giá khả năng sinh axit hũu co và polysaccharide ngoại bào (EPS) của chủng nấm TTHF1-3

Mức độ sinh axit hữu cơ của các chủng nấm được thực hiện theo mô tả của Liaud và cộng sự [26]. Nấm sợi được nuôi trên môi trường lỏng có thành phần như sau: Môi trường $\mathrm{MT} 1(\mathrm{~g} / \mathrm{L})$ : 5,0 g glucose; 0,7 g KH $\mathrm{KH}_{2} \mathrm{PO}_{4} ; 0,7 \mathrm{~g} \mathrm{~K}_{2} \mathrm{HPO}_{4}$;

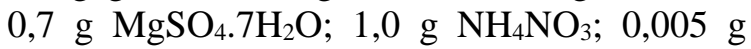
$\mathrm{NaCl} ; \quad 0,002 \quad \mathrm{~g} \quad \mathrm{FeSO}_{4} .7 \mathrm{H}_{2} \mathrm{O} ; 0,002 \mathrm{~g}$ $\mathrm{ZnSO}_{4} .7 \mathrm{H}_{2} \mathrm{O} ; 0,001 \mathrm{~g} \mathrm{MnSO}_{4} .7 \mathrm{H}_{2} \mathrm{O} ; 1000 \mathrm{ml}$ nước cất; $\mathrm{pH} 7,2$. Môi trường MT2 $(\mathrm{g} / \mathrm{L}): 1,0 \mathrm{~g}$ glucose; $3,0 \mathrm{~g}\left(\mathrm{NH}_{4}\right)_{2} \mathrm{SO}_{4} ; 0,1 \mathrm{~g} \mathrm{KH}_{2} \mathrm{PO}_{4} ; 0,5 \mathrm{~g}$ $\mathrm{MgSO}_{4} \cdot 7 \mathrm{H}_{2} \mathrm{O} ; 1000 \mathrm{ml}$ nước cất; $\mathrm{pH}$ 6,5. Các chủng nấm được nuôi cấy trên máy lắc với tốc độ 200 vòng/phút ở $30^{\circ} \mathrm{C}$ trong 5 ngày. Mức độ sinh axit hữu cơ được biểu thị bằng giá trị pH sau nuôi cấy ghi nhận trên máy đo $\mathrm{pH}$ (Semi-Micro pH meter; Mettler Toledo, Mỹ).

Khả năng sinh EPS của chủng nấm TTHF1-3 được thực hiện theo Ngo và cộng sự [27]. Chủng TTHF1-3 được nuôi cấy trong môi trường Czapek-Dox hiệu chỉnh giảm nồng độ đường saccharose $0,5 \%$ trong 72 giờ và dịch nuôi cấy chủng TTHF1-3 được ly tâm nhằm loại bỏ tế bào nấm. EPS thô từ dịch nuôi cấy được kết tủa ở $4{ }^{\circ} \mathrm{C}$ bằng việc bổ sung $96 \%$ ethanol theo tỷ lệ $1: 1(\mathrm{v} / \mathrm{v})$. Sau 24 giờ, mẫu tủa được ly tâm ở tốc độ 10.000 vòng/phút trong 15 phút và đông khô.

\section{Kết quả và Thảo luận}

\section{1. Đặc điểm mẫu vật kính ống nhòm gây hại bởi nấm sợi}

Quan sát mẫu thấu kính ống nhòm nhiễm nấm cho thấy, nấm sợi phát triển tập trung tại một số điểm và hệ sợi lan dần trên bề mặt thấu kính (Hình $1 \mathrm{AB}$ ), trong đó mũi tên chỉ vị trí sợi nấm phát triển và hình thành màng biofilm. Quan sát dưới kính hiển vi soi nổi cho thấy, nấm xâm nhiễm bắt đầu từ một vị trí và sợi nấm phát triển lan ra xung quanh tạo mạng hệ sợi 
màu trắng và xám (Hình $1 \mathrm{C})$, chứng minh hiện tượng đồng nhiễm các loài nấm có đặc điểm hình thái khác nhau.
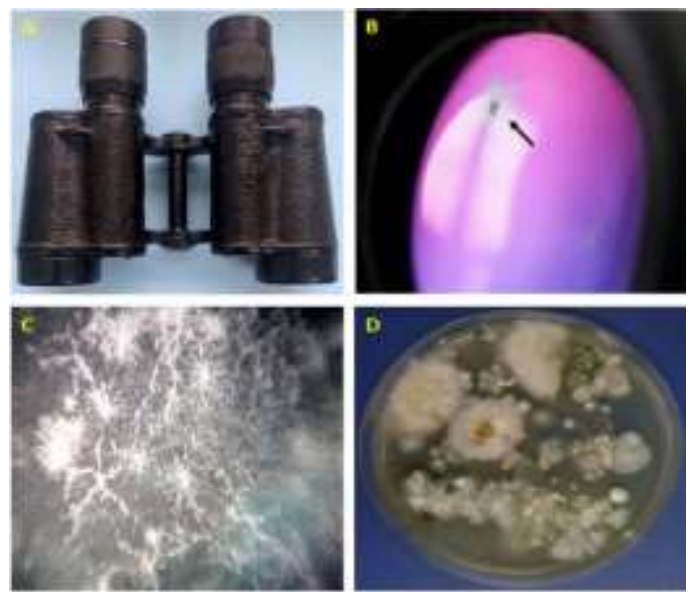

Hình 1. Nấm nhiễm trên thấu kính ống nhòm ON8x30. A-Mẫu ống nhòm thu thập; B-Thấu kính nhiễm nấm, mũi tên chỉ điểm nấm; C-Thấu kính ống nhòm nhiễm nấm được soi dưới kính hiển vi soi nổi (x28 lần); D-Nấm nhiễm kính được phân lập trên môi trường Czapek-Dox.

Kết quả đánh giá mật độ nấm cho thấy mật độ trung bình của nấm sợi trên 05 mẫu kính đạt $6,22 \times 10^{2} \mathrm{CFU} / \mathrm{cm}^{2}$. Nấm hình thái khuẩn lạc, màu sắc khác nhau (Hình $1 \mathrm{D})$. Các kết quả đạt được cho thấy, quá trình đồng nhiễm nấm xảy ra trên bề mặt thấu kính của ống nhòm. Mật độ trung bình của nấm sợi trong nghiên cứu này khá tương đồng với các công bố liên quan đến nấm gây hại kính Tu viện Cartuja de Miraflores, Burgos, Tây Ban Nha [28, 29], kính nhà thờ tại Belém do Pará, Brazil [14] và kính cửa sổ tại Mỹ [13].

\subsection{Phân lập và đánh giá mức độ gây hại của nấm sợi nhiễm trên thấu kinh ống nhòm}

Từ 05 mẫu thấu kính ống nhòm nhiễm nấm, đã phân lập 65 khuẩn lạc nấm và tuyển chọn được 23 chủng nấm đại diện theo hình thái và màu sắc. Phân tích các đặc điểm khuẩn lạc, hình thái hệ sợi và cuống sinh bào tử của các chủng đại diện cho thấy, các chủng nấm thuộc một số chi đại diện như Aspergillus, Curvularia, Nigrospora và Trichoderma (Bảng 1). Đánh giá mức độ gây hại của nấm sợi trên kính giả định cho thấy $11 / 23$ chủng nấm phát triển và gây hại trên bề mặt kính giả định bao gồm: mức độ 1 (1/11 chủng, 9,09\%), mức độ 2 (6/11 chủng; $54,55 \%)$ và mức độ 3 (4/11 chủng, $36,4 \%)$. Trong số các chủng thử nghiệm, chủng TTHF1-3 được ghi nhận ở mức độ gây hại mạnh nhất với diện tích sợi nấm bao phủ $29,77 \%$ bề mặt kính và mức độ truyền ánh sáng giảm 40-48\% so với đối chứng (Hình 2).

Bảng 1. Đặc điểm hình thái khuẩn lạc và bào tử của một số chủng nấm đại diện

\begin{tabular}{|c|c|c|c|}
\hline $\begin{array}{l}\text { Kí hiệu } \\
\text { chủng }\end{array}$ & $\begin{array}{l}\text { Hình ảnh } \\
\text { khuẩn lạc }\end{array}$ & $\begin{array}{c}\text { Hình ảnh } \\
\text { bào tử }\end{array}$ & Phân loại sơ bộ \\
\hline TTHF1-1 & & & Curvularia sp. \\
\hline TTHF1-2 & & & A speraillus sn \\
\hline TTHF3-3 & & & Niarosnora $\mathrm{sn}$ \\
\hline TTHF5-3 & & & Trichodorma on \\
\hline
\end{tabular}

Nghiên cứu thử nghiệm trên bề mặt kính giả định cho thấy, chủng nấm TTHF1-3 có khả năng sử dụng được nguồn dinh dưỡng tối thiểu để phát triển và phá huỷ trên bề mặt kính. Đặc tính này tương tự như các chủng nấm thuộc các chi Cladosporium, Phoma [12], Aspergillus và Penicillium [27] đã được ghi nhận trong các nghiên cứu trước đây. Vì vậy, cần nghiên cứu sâu hơn về đặc điểm phân loại, đặc tính sinh axit hữu cơ và EPS của chủng nấm TTHF1-3.

\section{3. Đặc điểm hình thái chủng nấm TTHF1-3}

Quan sát trên môi trường PDA cho thấy hệ sợi của chủng nấm TTHF1-3 phát triển chậm (Hình $3 \mathrm{~A}$ ) và hình thành thể quả có mầu nâu tối cho đến mầu đen, có hình dạng oval cho đến cầu với kích thước 225-350 x 200-350 $\mu \mathrm{m}$. Thành của 
thể quả có cấu tạo phức tạp, hệ sợi cứng bên cạnh mầu nâu tối, thon nhỏ về phần đỉnh và ít lượn sóng, hơi giáp, có đường kính $3-5 \mu \mathrm{m}$ và phần ngọn rộng 3-4 $\mu \mathrm{m}$ (Hình 3B). Bào tử túi hình hạt chanh, mầu đỏ nhạt khi còn non sau chuyển sang mầu nâu xám hoặc nâu sẫm, kích thước khoảng 8,5-11 x 7,0-8 $\mu$ m (Hình 3C)
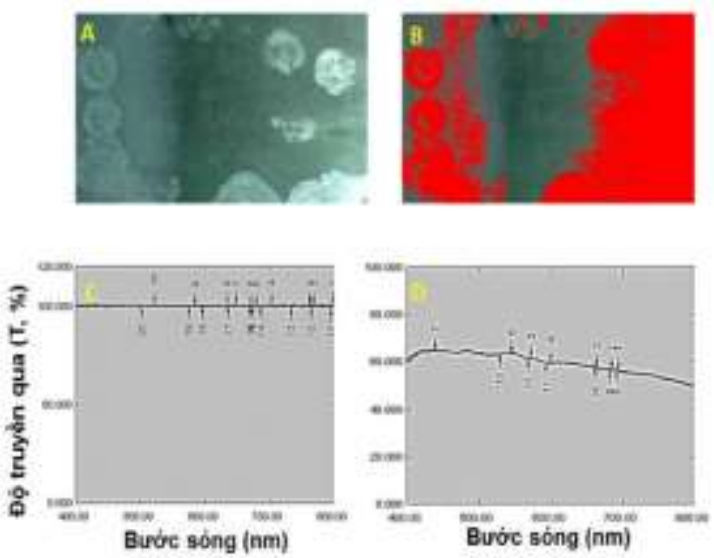

Hình 2. Mức độ gây hại của chủng nấm TTHF1-3 trên mô hình kính giả định sau 28 ngày. A-Nấm phát triển sau lây nhiễm trên kính; B-Phạm vi gây hại của nấm trên kính (nhuộm ảnh bằng công cụ ImageJ); $\mathrm{C}$ : Mức độ truyền qua của ánh sáng trên kính đối chứng (không nhiễm nấm); D-Mức độ truyền qua của ánh sáng trên kính (sau khi sửa sạch bằng ethanol) gây hại bởi chủng TTHF1-3.
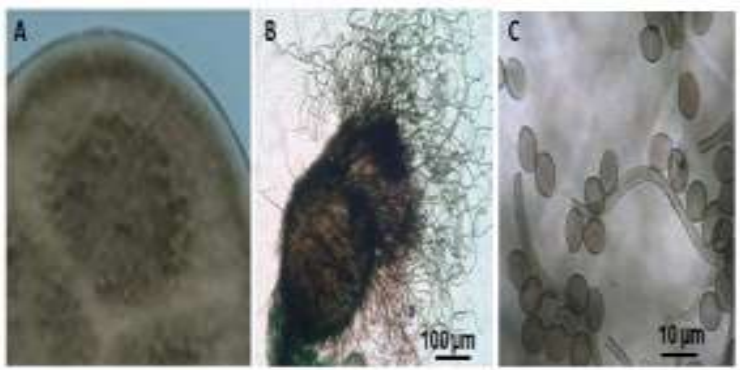

Hình 3. Đặc điểm hình thái chủng nấm sợi TTHF1-3.

A-Khuẩn lạc nấm phát triển trên môi trường thạch

$\mathrm{OA}$; B-Thể quả nấm được quan sát dưới kính hiển vi (x400 lần); và C-Bào tử nấm (x2000 lần).

3.4. Phân loại chủng nấm TTHF1-3 bằng phân tích trình tụ vùng gen ITS

Phân tích trình tự vùng gen ITS cho thấy chủng TTHF1-3 có độ tương đồng cao với các chủng nấm thuộc loài Chaetomium như Chaetomium pilosum CBS 335.67, C. cucumericola CBS 378.71, C. tectifimeti CBS 142032, C. citrinum CBS 693.82, C. capillare CBS $128489, C$. graminiforme CBS 506.84 và C. globosum NRRL 54669. Trong đó, chủng TTHF1-3 thể hiện độ tương đồng cao nhất với loài C. globosum NRRL 54669 (100\%). Quan sát cây phát sinh loài cho thấy, chủng nấm TTHF1-3 tạo thành nhóm riêng biệt với C. globosum CBS 148.51 và C. globosum NRRL 54669. Kết hợp với đặc điểm hình thái khuẩn lạc, quả thể, bào tử và phân tích trình tự vùng gen ITS, chủng TTHF1-3 được định danh thuộc loài Chaetomium globosum. Các công bố cho thấy $C$. globosum là loài nấm được tìm thấy trên bề mặt nhiều loại vật liệu như giấy, đá tự nhiên, gạch [30]. C. globosum được chứng minh có khả năng phân huỷ vật liệu composite như sợi polypropylene, sợi gai trong môi trường có độ ẩm cao $[31,32]$. Ngoài ra, C. globosum là một trong những nấm gây hại trên giấy và sợi được tìm thấy ở bảo tảng lịch sử ở Havana, Cuba [33]. Hiện chưa có nghiên nào công bố C. globosum có khả năng gây hại trên vật liệu kính (Bảng 2, Hình 4).

Bảng 2. Khả năng sinh axit hữu cơ và EPS của chủng nấm C. globosum TTHF1-3

\begin{tabular}{|l|c|c|c|}
\hline \multirow{2}{*}{$\begin{array}{l}\text { Chủng nấm } \\
\text { thử nghiệm }\end{array}$} & \multicolumn{2}{|l|}{$\mathrm{pH}$ môi trường } & $\begin{array}{c}\text { Hàm } \\
\text { lượng }\end{array}$ \\
\cline { 2 - 3 } & $\mathrm{MT} 1$ & $\mathrm{MT} 2$ & $\begin{array}{c}\text { EPS } \\
(\mathrm{g} / \mathrm{L})\end{array}$ \\
\hline $\begin{array}{l}\text { C. globosum } \\
\text { TTHF1-3 }\end{array}$ & $3,12 \pm 0,12$ & $4,26 \pm 0,18$ & $8,2 \pm 0,3$ \\
\hline
\end{tabular}

3.5. Đánh giá khả năng sinh axit hũu co và polysaccharide ngoại bào (EPS) của chủng C. globosum TTHF1-3

Sau 72 giờ nuôi cấy, giá trị pH sau nuôi cấy giảm mạnh nhất ở môi trường MT1 (từ $\mathrm{pH}$ 6,5 xuống $\mathrm{pH} 3,1$ ). Các nghiên cứu cho thấy, nấm gây hại trên vật liệu kính có khả năng làm giảm $\mathrm{pH}$ môi trường nuôi cấy và phổ sinh axit hữu cơ cao hơn nấm phân lập từ nước, nội sinh, đất $[5,8,9]$. Trên vật liệu kính, các chi Penicillium, Aspergillus và Cladosporium được tìm thấy khá 
phổ biến nhất gây ăn mòn và sinh nhiều loại axit hữu cơ formic, citric, acetic, oxalic, gluconic và itaconic $[34,35]$. Tuy nhiên, chưa có công bố ghi nhận khả năng sinh tổng hợp axit hữu cơ của $C$. globosum.

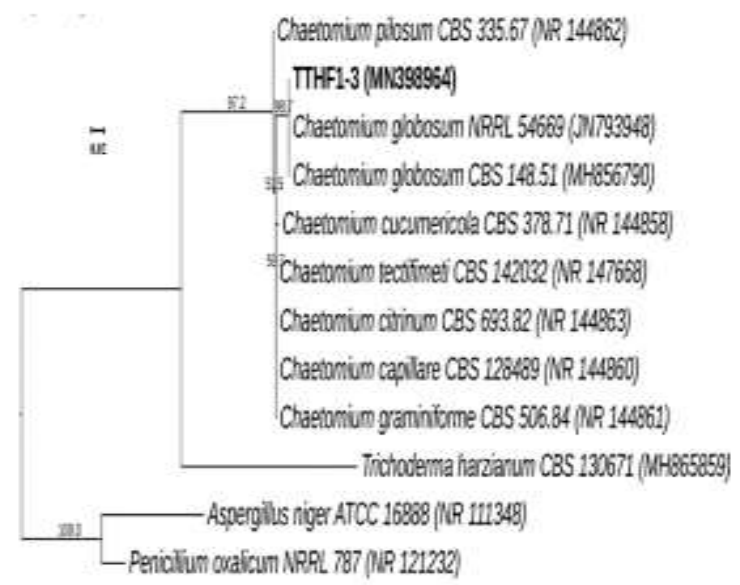

Hình 4. Cây phát sinh loài của chủng TTHF1-3 và các chủng đại diện tham chiếu với giá trị Boostrap 1000 sử dụng thuật toán Gamma và

Kimura 2. Chủng Aspergillus niger ATCC 16888 và Penicillium oxalicum NRRL 787 sử dụng làm nhóm ngoài.

Trong nghiên cứu này, chủng nấm C. globosum TTHF1-3 sinh tổng hợp 8,2 $\pm 0,3 \mathrm{~g} / \mathrm{L}$ EPS sau 5 ngày nuôi cấy. Ngo và cộng sự (2021) công bố các chủng nấm thuộc chi Penicillium, Aspergillus, Curvularia, Talaromyces sinh tổng hợp EPS trong dải 7-15 g/L khi nuôi trong môi trường Czapek-Dox có hiệu chỉnh. Điều này khẳng định khả năng sinh EPS của chủng $C$. globosum TTHF1-3 đạt mức thấp so với các nấm gây hại trên thấu kính. Cho tới nay, chỉ có nghiên cứu duy nhất báo cáo rằng nấm nội sinh $C$. globosum CGMCC 6882 phân lập từ cây giảo cổ lam (Gynostemma pentaphyllum) có khả năng sinh $2,1 \pm 0,2 \mathrm{~g} / \mathrm{L}$ EPS trên môi trường tối ưu [36]. Điều này góp phần khẳng định giả thuyết, khả năng sinh EPS là đặc tính nổi trội của các chủng nấm gây hại trên kính. EPS làm tăng tính bám dính bề mặt kính của nấm TTHF1-3. Đồng thời, EPS là thành phần quan trọng của biofilm giúp bảo vệ tế bào nấm khỏi những tác động xấu của môi trường và hấp thụ dinh dưỡng.

\section{Kết luận}

Từ 05 mẫu thấu kính trên ống nhòm nhiễm nấm tại Thái Hoà, Nghệ An, đã phân lập và định danh được chủng nấm TTHF1-3 thuộc loài Chaetomium globosum. Chủng nấm sinh trưởng mạnh và phát triển mạnh trên bề mặt kính giả định với diện tích sợi nấm bao phủ đạt $29,77 \%$, tương ứng mức gây hại thứ 2 theo tiêu chuẩn ISO 9022-11:2015. Bên canh đó, $C$. globosum TTHF1-3 sinh axit hữu cơ làm giảm $\mathrm{pH}$ trường nuôi cấy tới $\mathrm{pH} 3,12 \pm 0,12$ và $\sinh 8,2 \pm 0,3 \mathrm{~g} / \mathrm{L}$ EPS. Các kết quả thu được khẳng định đặc tính phân huỷ sinh học của chủng TTHF1-3 và tạo tiền đề cho những nghiên cứu sâu hơn giải mã cơ chế gây hại trên vật liệu kính trong tương lai.

\section{Lời cảm ơn}

Nghiên cứu được tài trợ Viện Hàn lâm Khoa học và Công nghệ Việt Nam dưới đề tài mã số TĐCNSH.05/20-22.

\section{Tài liệu tham khảo}

[1] Daniela Pinna, Biological Growth on Stone Heritage Objects: Methods, Products, Applications, and Perspectives, Apple Academic Press, 2017.

[2] R. D. Watkins, Mould in Optical Instruments, Community Eye Health, 2003.

[3] S. Bindschedler, G. Cailleau, E. Verrecchia, Role of Fungi in the Biomineralization of Calcite, Minerals, 2016.

[4] A. Rodrigues, S. G. Patricio, A. Z. Miller et al., Fungal Biodeterioration of Stained-glass Windows, International Biodeterioration and Biodegradation, Vol. 90, 2014, pp. 152-160.

[5] G. M. Gadd, Geomycology: Biogeochemical Transformations of Rocks, Minerals, Metals and Radionuclides by Fungi, Bioweathering and Bioremediation, Mycological Research, Vol. 111, 2007, pp. 3-49.

[6] H. Hocheng, M. Chakankar, U. Jadhav, Biohydrometallurgical Recycling of Metals from Industrial Wastes, CRC Press, 2017.

[7] Z. Li, L. Liu, J. Chen, H. Teng, Cellular Dissolution at Hypha-and Spore-mineral Interfaces Revealing Unrecognized Mechanisms and Scales of Fungal Weathering, Geology, Vol. 44, 2016, pp. 319-322.

[8] S. Gaind, Phosphate Dissolving Fungi: Mechanism and Application in Alleviation of Salt Stress in 
Wheat, Microbiological Research, Vol. 193, 2016, pp. 94-102.

[9] M. Gong, P. Du, X. Liu, C. Zhu, An Effective Method for Screening and Testing the True Phosphate-solubilizing Fungus that Enhances Corn Growth, Journal of Agricultural Science, Vol. 6, No. 9, 2014, pp. 60-70.

[10] M. Fomina, S. Hillier, J. M. Charnock, K. Melville et al., Role of Oxalic Acid Overexcretion in Transformations of Toxic Metal Minerals by Beauveria caledonica, Applied Environmental Microbiology, Vol. 71, 2005, pp. 371-381.

[11] M. G. Vallès, D. G. Torrente, S. M. Manent, I. L. F. Turiel, Medieval Stained Glass in a Mediterranean Climate: Typology, Weathering and Glass Decay, and Associated Biomineralization Processes and Products, American Mineralogist, Vol. 88, 2003, pp. 1996-2006.

[12] G. Piñar, M. G. Valles, D. G. Torrente, J. L. F. Turiel, J. Ettenauer, K. Sterflinger, Microscopic, Chemical, and Molecular-biological Investigation of the Decayed Medieval Stained Window Glasses of Two Catalonian Churches, International Biodeterioration and biodegradation, Vol. 84, 2013, pp. 388-400.

[13] M. Mansour, N. A. Rahim, M. Salem, Study of the Biodeterioration of some Stained Glasses by the Fungus Stemphylium botryosum, Current Science International, Vol. 5, 2016, pp. 119-129.

[14] A. M. C. Pinto, T. Palomar, L. C. Alves et al., Fungal Biodeterioration of Stained-glass Windows in Monuments from Belém do Pará (Brazil), International Biodeterioration and Biodegradation, Vol. 138, 2019, pp. 106-113.

[15] F. Pinzari, M. Montanari, Mould Growth on Library Materials Stored in Compactus-type Shelving Units, in Sick Building Syndrome, 2011, pp. 193-206.

[16] K. Sterflinger, G. Piñar, Microbial Deterioration of Cultural Heritage and Works of Art-tilting at Windmills, Applied Microbiology and Biotechnology, Vol. 97, No. 22, 2013, pp. 9637-9646.

[17] D. V. H. Mien, Mold System in Vietnam: Classification, Harm, Toxins, Prevention, Science and Technics Publishing House, 2015, pp. 475-479 (in Vietnamese).

[18] V. M. Thanh, L. D. Anh, N. M. Tien, D. V. Long, D. T. Anh, T. Khuong, P. T. Anh, T. D. Dinh, T. T. T. Cuc, Determining Mechanism of Blurring the Optical Glass and the Chemical Composition of Optical Anti-blur Coating in Offshore Environment, Journal of Military Science and Technology, Vol. 26, 2013, pp. 100-106 (in Vietnamese).

[19] A. Hayes, Some Microfungi from Scots Pine Litter, Transactions of the British Mycological Society, Vol. 48, 1965, pp. 179-185.
[20] Standard, Unified System of Corrosion and Ageing Protection, Non-metallic Materials and Articles with Their Application, Method of Microbiological Resistance Tests under Natural and Atmospheric Conditions, Russia, 1975 (in Russian).

[21] K. A. Seifert, W. Gams, The Genera of Hyphomycetes-2011 Update, Persoonia: Molecular Phylogeny and Evolution of Fungi, Vol. 27, 2011, pp. 119.

[22] Bureau of Standards and Quality, Handbook of Optical Standard Room Methods, Calibration Method for Absorbance, Transmittance, Ministry of National Defence, 2009, pp. 1-4 (in Vietnamese).

[23] K. Ihrmark et al., New Primers to Amplify the Fungal ITS2 Region-evaluation by 454-sequencing of Artificial and Natural Communities, FEMS Microbiology Ecology, Vol. 82, 2012, pp. 666-677.

[24] J. Felsenstein, Phylogenies and the Comparative Method, The American Naturalist, Vol. 125, 1985, pp. 1-15.

[25] S. Kumar, G. Stecher, K. Tamura, MEGA7: Molecular Evolutionary Genetics Analysis Version 7.0 for Bigger Datasets, Molecular Biology and Evolution, Vol. 33, 2016, pp. 1870-1874.

[26] N. Liaud, C. Ginies, D. Navarro, N. Fabre, S. Crapart, I. Herpoel-gimbert, A. Levasseur, S. Raouche, J. C. Sigoillot, Exploring Fungal Biodiversity: Organic Acid Production by 66 Strains of Filamentous Fungi, Fungal Biology and Biotechnology, Vol. 1, No. 1, 2014, pp. 1-10.

[27] C. C. Ngo et al., Identification of Fungal Community Associated with Deterioration of Optical Observation Instruments of Museums in Northern Vietnam, Applied Sciences, Vol. 11, No. 12, 2021, pp. 5351.

[28] N. Carmona et al., Biodeterioration of Historic Stained Glasses from the Cartuja de Miraflores (Spain), International Biodeterioration and Biodegradation, Vol. 58, No. 3-4, 2006, pp. 155-161.

[29] M. Bartosik, Z. Zakowska, K. Cedzinska, K. Rozniakowski, Biodeterioration of Optical Glass Induced by Lubricants Used in Optical Instruments Technology, Pol, J. Microbiol, Vol. 59, No. 4, 2010, pp. 295-300.

[30] A. M. Lewinska et al., Visualization of the Structural Changes in Plywood and Gypsum Board During the Growth of Chaetomium Globosum and Stachybotrys Chartarum, Journal of Microbiological Methods, Vol. 129, 2016, pp. 28-38.

[31] B. Crawford, S. Pakpour, N. Kazemian, J. Klironomos, K. Stoeffler, D. Rho, J. Denault, A. S. Milani, Effect of Fungal Deterioration on Physical and Mechanical Properties of Hemp and Flax Natural Fiber Composites, Materials, Vol. 10, No. 11, 2017, pp. 1252. 
[32] M. R. Fogle, D. R. Douglas, C. A. Jumper, D. C. Straus, Growth and Mycotoxin Production by Chaetomium globosum is Favored in a Neutral pH, International Journal of Molecular Sciences, Vol. 9, No. 12, 2008, pp. 2357-2365.

[33] T. L. Rojas et al., Fungal Biodeterioration in Historic Buildings of Havana (Cuba), Grana, Vol. 51, No. 1, 2012, pp. 44-51.

[34] J. K. Magnuson, L. L. Lasure, Organic Acid Production by Filamentous Fungi, in: Advances in
Fungal Biotechnology for Industry, Agriculture, and Medicine, Springer, 2004, pp. 307-340.

[35] J. L. Weaver, P. T. DePriest, A. E. Plymale, C. I. Pearce, B. Arey, R. J. Koestler, Microbial Interactions with Silicate Glasses, NPJ Materials Degradation, Vol. 5, 2021, pp. 1-18.

[36] Z. Wang et al., Characterization and Anti-inflammation of a Polysaccharide Produced by Chaetomium globosum CGMCC 6882 on LPS-induced RAW 264.7 Cells, Carbohydrate Polymers, Vol. 251, 2021, pp. 117-129. 